\title{
Advancing a social justice agenda in health professions education
}

\author{
Cecilia Jacobs", Susan Van Schalkwyk, Julia Blitz and Mariette Volschenk \\ Centre for Health Professions Education: Stellenbosch University \\ "Corresponding author: jacobsc@sun.ac.za
}

(Submitted: 21 April 2020; Accepted: 30 July 2020)

\begin{abstract}
Health Professions Education (HPE) curricula have a dual purpose: to deliver professionals who are clinically competent and critically conscious of the contexts and health systems they serve. This qualitative study advances a social justice agenda by exploring the range of understandings that HPE teachers have of this dual purpose of their curricula. Thirty-four respondents participated in eleven focus groups and eleven interviews. Data were analysed thematically. While participants understood this dual purpose of their curricula, some felt that clinical competence should be emphasised above critical consciousness. Implementing curricula that develop critically conscious graduates raises questions about what counts as knowledge, and about how far our responsibility extends in preparing students to become change agents. This has implications for the role and identity of the HPE teacher and points to a re-envisioning of the process of curriculum development and the role that HPE centres play in the process of curriculum development.
\end{abstract}

Keywords: Critical Consciousness, Higher Education, Health Professions Education, Responsive curricula, Social Justice

\section{Introduction}

A curriculum is tantamount to a blueprint for what is taught, and how it is taught and assessed (Scott, 2008). However, the interpretation of this blueprint does not occur in a vacuum; rather it is influenced by the context within which it is implemented, the context for which it is being taught, and the principles upon which it has been based. Ultimately, it is the educator who breathes life into the curriculum, bringing her own norms, values, experience, and expertise into the educational space. In South Africa, where the realities of health inequity, the burden of disease and service in resource-constrained environments dominate, curricula need to deliver relevant healthcare professionals who are not only clinically competent but also critically conscious (Freire, 2000) of the contexts in which they serve and the health care systems within which they practice - thus curricula that are responsive to issues of social justice. An imperative for exploring a more responsive curriculum framework for healthcare professionals has been established in previous 
work in the field of Health Professions Education (HPE), such as the seminal Lancet Report (Frenk, et al., 2010), as well as Bleakley, et al. (2008) and Kuper, et al. (2016), and echoes theorists from the higher education sector, such as Dall'Alba and Barnacle (2007) and Barnett (2009). The study reported in this paper sought to respond to these imperatives and calls for HPE curricula to be more responsive and relevant to the social contexts in which they are located, while advancing a social justice agenda in HPE.

\section{Background and context}

The background to this study arises from three inter-related areas: calls from within the HPE sector, shifts in the literature on HPE, and the context of South Africa. South Africa is overwhelmed by a burden of disease and health inequity, both of which demand responsive healthcare curricula. Lebel and McLean (2018: 24) argue that research needs to be 'grounded in, and applicable to, the local experience', thereby offering unique solutions to unique problems. They further argue that those most closely linked to a particular problem are best placed to develop a solution. While the healthcare challenges facing South Africa are not unique, the way in which the field of HPE responds will be shaped by the local HPE teachers ${ }^{1}$ at the coalface of curriculum delivery. Mayosi and Benatar (2014: 1344) outline the health imperatives facing South Africa 20 years after the democratic elections in 1994. They describe the reality as 'plagued by a relentless burden of infectious and noncommunicable diseases, persisting social disparities, and inadequate human resources to provide care for a growing population with a rising tide of refugees and economic migrants'. Linked to this is South Africa's status as the most unequal society in the world, with the highest Gini coefficient ${ }^{2}$. According to the World Bank, the poorest $20 \%$ of the South African population consume less than $3 \%$ of total expenditure, while the wealthiest $20 \%$ consume 65\%. In order to improve access to healthcare in South Africa, Mayosi and Benatar (2014) list one of the priorities as high-quality teaching in the training of healthcare professionals. They also state that there is too great an emphasis on biomedicine as a dominant route to improved health, suggesting that more consideration should be given to the social determinants of health i.e. social injustices that affect health outcomes (Marmot, 2005). This has implications for HPE curricula at South African universities.

A clarion call has also come from within the field of HPE in the form of the Lancet Report (Frenk, et al., 2010, 5) which states that HPE has not kept pace with the challenges of healthcare systems, 'largely because of fragmented, outdated, and static curricula that produce ill-equipped graduates' and that a redesign of professional health education was necessary. The report proposes Mezirow's (1990) 'transformative learning' as a lens for curriculum reform and suggests that the widely-accepted competency-based model for HPE curricula be adapted to the rapidly changing local conditions. 'Transformative learning' is understood as developing leadership attributes and producing enlightened change agents who are able to speak back to social ills. In

\footnotetext{
${ }^{1}$ By the term 'HPE teacher' we are referring to those who teach on HPE programmes, including both those teaching 'in the classroom' and those teaching 'in the clinical areas'.

${ }^{2} \mathrm{~A}$ measure representing the income or wealth distribution of a nation's residents.
} 
adapting the HPE curricula, the report recommends that technical competence be blended with a service orientation, and that this blended curriculum needs to be 'steered by ethical commitment and social accountability' (Frenk, et al., 2010: 7). They point to a 'mismatch of professional competencies to patient and population priorities' and state that health professionals need to appreciate the human rights dimensions of their work. Furthermore, the report points to the importance of responsiveness to context, and the need to 'adapt competency-based goals for local effectiveness rather than to adopt models from other contexts that might not be relevant' (Frenk, et al., 2010: 28).

At national level, the Academy of Science of South Africa (ASSAf) responded to the Lancet Commission's recommendations by publishing a consensus study report with detailed evidencebased pedagogic and system recommendations on the transformation of HPE as a means to improve quality care and patient outcomes in the South African context (ASSAf, 2018; Volmink, 2018). The report foregrounds the reconceptualisation of HPE with a view to producing 'knowledgeable, competent, relevant, socially accountable health care providers capable of confidently and collaboratively promoting health and addressing the country's burden of disease across the continuum of healthcare in the context of quality universal health coverage' (ASSAf, 2018: 33). The report advocates for the development of change agency and responsiveness at the levels of higher education institutions, curricula, educators and students. The adoption of a hybrid competency-based education model that facilitates transformative collaborative learning at undergraduate level across professional boundaries is further proposed as a means to promote high quality, equitable health care delivery (ASSAf, 2018). Professional education is, therefore, viewed as a crucial component in addressing the health challenges of our times and moving closer to a world that aspires to equitable access to health. The challenge for HPE teachers is translating these calls into renewed HPE curricula and transforming their teaching and assessment practices to take account of the contexts in which their students will serve and the health care systems within which they will practice.

\section{Literature review}

This study is informed by two bodies of knowledge: Higher Education (HE) Studies and HPE Studies. In the body of work emanating from the field of HE studies, curriculum renewal fits within the broader context of institutional transformation and raises questions about what kind of university is needed to respond to the context of South Africa. Luckett and Shay (2017) argue that HE is structured to serve the interests of 'the haves' at the expense of the 'have-nots' and that higher education needs to be reclaimed as a 'public good'. They further claim that HE has come to be viewed as a 'private' good, 'to be bought and sold in competitive markets to students-as-consumers' (2017: 2). HE curricula seem to be training students solely for the purpose of entering a vocation, as opposed to supporting students on a journey of 'intellectual emancipation' (Samuel, et al., 2016; Van Schalkwyk, et al., 2012). Bawa (2018) highlights the need for universities to revisit what the purpose of $\mathrm{HE}$ is and what the purpose of a university is. $\mathrm{He}$ argues that universities need to create 'intellectual, social and physical meshes between 
themselves and the struggles and aspirations of their publics, as both universities and their publics are shaped by these interactions'. We locate this work within a view that sees HE as a public good with a purpose beyond that of narrow vocational training. Curricula play a crucial role in creating meshes between universities, and the struggles and aspirations of the publics they serve.

Butler-Adam (2018: 1) contends that '[s]tudents studying the basic and applied sciences need also to understand the political and social natures of the world in which they live'. This contention speaks to a different kind of basic and applied sciences curriculum. Our study explores what this might mean for HPE curricula. Luckett and Shay (2017) argue that curriculum renewal can be one means of challenging and dismantling injustices and inequalities in society. They suggest that one of the issues that needs to be interrogated, are assumptions informing the norms of curricula, and that in order to do that, all academic staff need to rethink their curricula and pedagogic practices. In 2007 Dall'Alba and Barnacle argued for an 'ontological turn' in higher education. In their seminal work, they explore the need to foreground ontological concerns in a system which has been dominated by epistemological concerns. They make a case for the integration of knowing-acting-being in HE programmes and argue that we need to prepare students for making a contribution to society. Such a focus, they suggest, should be explicit in curriculum design. In earlier work, on which Dall'Alba and Barnacle draw, Barnett (2005) presents the case for an 'ontological turn' in HE teaching. He argues that 'epistemology and ontology are irreducible to each other but are interlinked' (Barnett, 2005: 437) and that curricula have to be concerned with knowledge, skills, and attitudes. 'Knowledge' refers to the disciplinary content knowledge that students need to know in programmes and modules, while 'skills' refer to the practical application of that knowledge, or what students need to do with that knowledge. While these two domains are well understood in HPE curricula, the domain of 'attitudes' refers to the values or kinds of attributes that HPE teachers want to develop in their students, or what kind of people they want their students to become as a result of the teaching and learning taking place in programmes and modules. This domain, for the HPE curricula, would be about being and becoming a future healthcare professional, as well as developing the habits of mind required to be a clinically competent but also a critically conscious healthcare professional in South Africa. This also has implications for the role and identity of the HPE teachers who deliver these curricula. To achieve this interconnectedness at curriculum level, according to Barnett (2005: 440), requires 'a thinking through of the kinds of human being that we want our students to become'. Such thinking implies going beyond the reform of curricula and adopting transformative approaches to curriculum renewal. Luckett and Shay (2017) state that curriculum transformation needs to take us beyond 'affirmation' and 'assimilation' and 'reform'. Instead, a transformative approach to curriculum should consciously address questions of difference and power and 'work with competing and contradictory socio-historical narratives and identities that staff and students bring to the classroom' (2017: 11).

Literature in the field of HPE has much to offer towards the notion of developing clinically competent healthcare professionals who are also critically conscious. The concept of reflective 
practice (Schön, 1983) provides a lens for thinking about how to develop curricula which deliver relevant healthcare professionals who are both clinically competent and critically conscious. Ng, et al. (2015) review medical education literature, from 2004 to 2014, to explore how the concept of reflective practice has been applied to undergraduate and postgraduate medical education. They found that dominant trends were utilitarian, self-focused and assessment driven, and that the potential for reflective practice as a way of being, what Mezirow (1990) terms 'critical reflection', was limited. Drawing on Mezirow's work they use the term to mean 'more explicit attention to social and systemic forces, and the assumptions embedded in thought processes and power relations, with an aim toward transformation and action' (Ng, et al., 2015: 465). They call for a shift beyond the biomedical model in medical education, 'beyond [cultural] competence, toward a Freire-inspired critical consciousness' ( $\mathrm{Ng}$, et al., 2015: 465). These ideas are fundamental to our study and we draw on Freire's (2000: 73) reference to 'critical consciousness' as 'intervention in the world as transformers of that world'. Specifically, we are using the term critical consciousness to refer to health professionals (including those in training) who question the causes of health inequity and intervene in health care contexts and systems with a view to transforming them into more socially just spaces.

$\mathrm{Ng}$, et al. (2015) further suggest that medical education's competency-based approach to curriculum, teaching and assessment encourages reductionist mindsets. According to Whitehead, et al. (2011: 1) competency frameworks are being used extensively in HPE internationally, and they cite the CanMEDS competency framework as 'one of the most successful and widely used models'. The way in which the CanMEDS competency framework has been understood and implemented reduces the development of future healthcare professionals to a series of roles, with the role of 'medical expert' at the centre, and what is often referred to as 'non-medical expert roles' (Kuper, et al., 2016) at the periphery. This positioning and nomenclature has been challenged by Sherbino, et al. (2011) who see these so-called 'non-medical' roles as 'intrinsic roles'. The CanMEDS framework, and the role definitions therein, are also widely used in South African HPE, and what this study will consider is the social and contextual nature of these 'intrinsic roles' (professional, health advocate, collaborator, leader, communicator, and scholar) and how their teaching can play a role in the processes of students being and becoming critically conscious healthcare professionals.

A further dimension of this discussion is found in the work of Bleakley, et al. (2008) who bring into dialogue post-colonial theory and the field of medical education. They critique the framing of the medical curriculum as an 'international text' and the exporting of Western models and values, such as the notion of a competency-based curriculum. They further question whether a uniform approach to 'professionalism' and to 'non-technical skills' in clinical practice is in fact appropriate. Drawing on the body of knowledge from comparative medical education, they raise issues such as the lack of attention to community health and an education system that is diseaseoriented rather than patient-oriented. Instead, they argue for a medical curriculum that addresses local concerns and post-colonial problems. Post-colonial problems are inextricably linked to local political and economic systems, as well as world imperialism. Educating future healthcare 
professionals should then necessarily involve developing a critical consciousness of global health inequality and of the way in which global health is framed within a rhetoric of cost-effectiveness, rather than equity and social justice. These are the broader social issues we are referring to when we call for HPE curricula to be more responsive and relevant to the social contexts in which they are located. Addressing such issues involves more than just the diagnosis and management of disease. Disease is managed in the context of a healthcare system and addressing the issues of equity and social justice within local healthcare systems needs to become part of how educators teach future healthcare professionals. It is in this area that the study hopes to make a contribution.

\section{Methodology}

Much work has been done in the area of curriculum renewal in the Faculty of Medicine and Health Sciences at Stellenbosch University in response to calls for HPE curricula to be more responsive and relevant to the social contexts in which they are located. In the process of curriculum renewal these calls are translated into broad principles underpinning programmes of study. Such principles are often written up as broad philosophical statements by teams of curriculum designers. How these broad principles translate into teaching practices, in programmes of study, is less clear. The implementation of these principles is often incumbent on the understandings that HPE teachers have of such broad philosophical underpinnings. A disconnect between the intentions of curriculum designers and the understandings that HPE teachers have could have serious implications for the translation of such principles into the teaching practices of HPE teachers and the learning opportunities for future healthcare professionals. The purpose of the study was, therefore to explore the range of understandings that HPE teachers have, as they interpret the principles underpinning their HPE curricula which are designed to deliver future healthcare professionals who are not only clinically competent but also critically conscious of the contexts in which they serve and health care systems within which they practice. The research questions are framed as:

- How do the participating HPE teachers understand the broad principles upon which their curriculum is built?

- How are these understandings translated into innovative teaching practices?

Two purposively selected programmes in the Faculty of Medicine and Health Sciences at Stellenbosch University were included in the study, the MBChB and Physiotherapy programmes. These programmes were selected as both were in the process of curriculum renewal. Ethical approval was obtained from the Health Research Ethics Committee of the faculty. The programme co-ordinators and all module leaders for the two selected programmes were invited to participate in the study. Thirty-four respondents (including clinicians responsible for student learning in the clinical space) participated, twenty-six from the MBChB programme (M1 to M26) and eight from the Physiotherapy programme (P1 to P8). There was no sampling and all 
stakeholders participated voluntarily, with some participating in both the focus group sessions and the individual interviews. This ensured a variety of perspectives and triangulation of the data.

The data collection process included eleven focus group sessions with thirty-one of the participants (coded as FG1 to FG 11) and individual interviews with eleven programme coordinators, module leaders and HPE teachers. Broad principles and philosophical statements underpinning the curricula were used as a stimulus and a point of reference for the focus group sessions and individual interviews. The focus group sessions focussed predominantly on the first research question, while the individual interviews focussed predominantly on the second research question. All focus group sessions and interviews were recorded, transcribed, coded and analysed through a process of thematic analysis (Braun and Clarke, 2006). To ensure the credibility and trustworthiness of the data analysis process a coding framework was developed collaboratively among the research team after a process of open-coding of the transcripts. This coding framework was then extended and refined collaboratively as the analysis of transcripts proceeded, after which a thematic meta-analysis was conducted across all transcripts to identify the cross-cutting themes.

\section{Findings}

In answer to the research questions, the findings provided insights into how the participating HPE teachers understood the broad principles upon which their curriculum was built, as well as how their understandings translated into innovative teaching practices. The first research question referred to how respondents understood the broad principles underpinning their curricula.

\section{Understandings of curriculum principles}

The findings indicated that the HPE teachers on the two programmes all agreed that their curricula needed to be socially responsive and contextually relevant. One respondent (P5) expressed this as the need to address the 'context' and not just the 'impairments'. There was also general agreement that there was a need to develop students who were not only clinically competent, so 'that they don't exit just as a clinical robot'(M1), but also critically conscious of the contexts in which they will serve and the health care systems within which they will practice:

I think young doctors need to see, at some level, they need to have a sense of my role is to make a difference in society. (M26)

However, how the respondents understood this need, varied across the participants. While some respondents understood the development of a critical consciousness in their students as a graduate attribute that needed to be bedded down into the learning outcomes of their curricula, others understood it in more complex ways, as developing the professional identity of their students towards becoming future doctors and physiotherapists who were socially accountable. In one focus group session, accountability was expressed in the following way: 
... accountability as not just being accountable for the service and being ethical and all of that, but making sure it's actually directed towards the needs of that community or that person or that family, and that your client management is person and family centred, maybe even to a larger scale, community or systems, and then, organizing your services appropriately according to those needs. (FG1)

In another focus group session the respondents expanded on the tension between social accountability and accountability to the individual patient:

I think that is where our aim should be, is how do we actually teach them to reflect on what is the social accountability and is it more important to think about the public health as a big problem, or is it not equally important to think about what is your social accountability to the patient in front of you ... it's a multifactorial problem if we think about health in the context of South Africa. So we should in essence do the economics, we should do social development ... I am hoping, in this curriculum, is that we are teaching them to reflect on their role, and what is going to be their part, either individual or as a team, healthcare team, in caring for our population in South Africa, over the spectrum from primary healthcare up to tertiary healthcare. (FG10)

Another way in which some respondents understood critical consciousness was developing future healthcare professionals as change agents, with an advocacy role and being responsive to contextual needs.

I think to create future doctors who are actually able to, who are graduating with a sound understanding of the health system they are going to be working in, and feeling confident that they don't just have to accept the status quo, but can actually have the tools to make a change. Because the difficulties, or the situation we are sitting with in South Africa, it's a big problem. It's not just a health problem. It's an inter-sectoral problem... I think to create a doctor that is resilient, who is positive to make the difference that they can be and that is needed for our healthcare and broader population in South Africa. (FG4)

While most respondents agreed that it was necessary for their curricula to make students aware of the causes of health inequity, not all respondents agreed that it was necessary for students to intervene in health care contexts and systems with a view to transforming them into more socially just spaces. Some respondents felt that this was a choice that individual students needed to make, as illustrated in the quotations below:

... I don't see social accountability as the doctor being the change agent and the answer to all the problems for everyone. It can't be. Social accountability is actually a social issue, which then includes all the members of society, and the health professionals just play a 
very specific role in that, but in a very specific - almost again I want to say - decided by an individual, in a sense as well. Where is the best fit for his or her passions, or things that he can contribute to the health of that society. (FG10)

I don't think you can expect everyone to be [a change agent]. Not everyone is going to go out and have the personality for that. But I think as long as they have some knowledge and some tools, what they then decide to do with that ... so again, you can't expect everyone to be change agents, but they must have tools to assess health systems and a community at a larger level. (FG1)

Some respondents went beyond the notion of students as change agents, and understood that it was necessary for their curricula to be underpinned by issues of social justice and human rights. One respondent expressed this understanding as:

There are two things I would like a student to maybe think about at least. The one is the concept of the greater good of the many ... the second part, everything is a balance ... an important balance has always been between rights and responsibilities. (M22).

In one focus group session, this understanding was expressed as:

I think that is the way that we should teach them from the beginning, around social justice. That should be the whole slant, because it encompasses caring, and it encompasses all of that. (FG2)

In summary, there was a range of understandings regarding what it meant to deliver curricula that were socially responsive and contextually relevant. These understandings included developing the professional identity of students; becoming future doctors and physiotherapists who were socially accountable; developing future healthcare professionals as change agents with an advocacy role and a responsiveness to contextual needs; as well as delivering curricula that were underpinned by issues of social justice and human rights. The next section explores how these understandings were translated into pedagogical approaches and teaching practices in both the academic environment as well as the clinical platforms.

\section{Pedagogies and teaching practices}

The second research question referred to how the understandings, which the respondents had of the broad principles underpinning their curricula, were translated into teaching practices. The findings revealed a range of teaching practices arising from the understandings that the HPE teachers had expressed. Respondents indicated that developing future graduates who are able to take up the challenges of healthcare in South Africa, required authentic and embodied learning experiences which were located in the 'real world', as expressed in the quotations below: 
We took them out into an authentic environment and gave them a taster. It's not just a lecture. It's actually, they hear a lecture, and then they see it for real ... exposing them to the structure that they are going to work in, but really transitioning that to seeing it for themselves. (FG3)

They are actually placed, the whole year, 30 weeks of clinical experience where it is workplace based, so they work in an authentic environment. (FG2)

... the idea is that with the student being within the clinical environment, within this real world authentic learning environment now, they are of course now presented with various patients, various scenarios, for them to deal with.(P4)

So immersion, so being in the space ... where you are actually having to do it, or in the practice or in the health system, actually asking people ... where they are actually having to speak to X, so they are immersed in it. So I think part of it is immersion. (FG3)

Respondents reported that placing students on clinical platforms and immersing them in communities was the best way to achieve authentic and embodied learning, and in turn develop a critical consciousness. Another pedagogical practice that came up in the data was using approaches which integrated medical and allied health students and promoted interprofessional discussions among them. This was usually done using real-world scenarios and service-learning projects. However, a number of respondents spoke to the difficulty of implementing interprofessional projects in both the academic and the clinical environments:

... just putting different professions together in the classroom, does that actually achieve anything? Somebody was remarking that with the current interprofessional phase that they have in first year in the class, you know that the physio is always going to sit in that corner, and the OT's in that corner, and the medics take up the rest. You know, that kind of thing. So, does that achieve anything? (M23)

... the interprofessional education we know is like a stop-start thing. It's very difficult to actually integrate it through, and we have identified that the main barrier is timetables, different programs, and also, that it is actually not happening in practice. So where we are placing our students, there is no model for them to do that ... So it's logistics, but I do think a mind-set change is also needed in terms of if you want to make it happen, you have to let go of something. So it has to be important enough. (P8) 
While many respondents commented on the difficulty of implementing interprofessional projects, there was general agreement that this was an important pedagogical practice towards developing a critical consciousness in students:

But if we can actually get students together in a clinical environment doing something practically, I think that can be much more meaningful in terms of collaborative practice, and collaborative practice has a significant effect in terms of students' understanding of the health system and of the community and of themselves. So I think it does address those things... you have to structure something. I don't think putting people there, because generally, as health professionals, we're not used to working in collaboration. We say we work in teams, but most of the time we don't. So I think it has to be structured ... we are struggling, to be honest ... we've got OT, physio and medicine students together, but they're not actually interacting. So we're trying to say how do we structure that to make sure they do interact, because it's very easy for them to just do their own thing and actually not see each other. (FG8)

Two other respondents suggested that the collaboration among disciplines needed to extend beyond the participating programmes:

... fostering this interprofessional learning and collaboration, it was a struggle. People are very strong in their silos ... it's not just one profession that can make the difference, and actually, as a Faculty we can't even make a difference anymore. We need inter-faculty, inter-university inter-sectoral collaboration to really address the determinants of health, because yes, we can give you a pill for TB, but if you still live in a house that is damp and wet and overcrowded, then you're just going to come back with MDR TB the next day ... I want engineering here, and I want law also within our Health Faculty, to really make an impact on society and the communities we work in. (P5)

I think it's definitely the initiative should come from the Faculty, but there should be buyin from the different programs. I think there has to be strong leadership if this is an outcome for this Faculty, that we want to focus on interdisciplinary, interprofessional, and even for social accountability. That would also be an ideal thing, because it's not something that is specific to physio or specific to medicine. We can definitely work together... Therefore, if it's like a central thing, then the Faculty should be the driver, not necessarily the doer, but the driver, and obviously investor, invest time and resources in developing that, and prioritising it. (P8)

When questioned about the best teaching practices for developing a critical consciousness in students, some respondents suggested that the best way to 'teach' this was through their modelling the practices and the values they were wanting to instil: 
But also, these principles ... should be modelled. That's how we often learn those more soft skills, is not around okay now guys, you have to sit down and self-reflect and write a reflective piece, but at the people who are teaching me embodying that, or modelling that, or sort of showing me how to be that. (FG3)

One respondent used role modelling by drawing on her own personal and practical experiences in her profession, as illustrated in the quotation below:

I would say more explicit role modelling ... I think I'm a very practical person, so I like using my own personal and practical experiences in class, and examples of case studies or an example of where I had to learn this. (FG1)

While most respondents were in agreement that critical consciousness, social accountability and contextual responsiveness were not 'skills' or something you could teach as a recipe, there was some doubt as to whether enough role modelling was taking place and whether the roles being modelled were made explicit to students:

... but our behaviours as well, to what extent I mean, hopefully we, I think we are all professional most of the time, but I don't think they get exposed enough to what it is that we do ... there is lack of role modelling in terms of all of these. (FG2)

So you can model it until you are blue in the face, but if they cannot recognise that you have modelled it, you know what I mean? You need to be explicit about it... So that's why I'm saying, there are a lot of things that we teach at the student, that just goes completely past them because they don't know that they must look out for that. (M2)

Reflection was the most common teaching practice shared by the respondents. They used reflection in two ways in their teaching, as a means of creating students' awareness and as a means of getting students to think about how to act on their awareness. Some of the ways that the participants used reflection as a means to raise their students' awareness of contexts and health care systems included: creating time for students to think critically and reflect on what they had been exposed to; debriefing students' exposure to the real world; teaching students how to reflect; stimulating students' self-awareness of their own worldviews; creating awareness of others' worldviews and the multiplicity of perspectives; and seeing the 'big' picture by going beyond just the disease and the individual presented to them.

Besides using reflection as a means of creating students' awareness, some respondents went further and used reflection as means of developing students' advocacy role and agency to bring about change. One respondent describes a task that attempts to not only raise students' 
awareness through reflection, but also gets students to think about how they might act on their awareness:

I do human rights with the students, and I get them to do a task on rights abuse. Not just ethical problems, rights abuse, that they have witnessed sometime in their training, and the task goes like this. They have to describe the incident that they have seen or a family member has seen, but it must be in the first person... So they describe the incident, and they then have to identify the different rights abuses that they see and relate those to the Bill of Rights. So they have to explain them, and then the last part is they have to explain what should or could have been done to change the incident. (P1)

This task, however, raised an ethical dilemma for this respondent:

My ethical problem is that although they can tell me, they don't have to act on it, because of the power differential between them and the clinicians.

This ethical dilemma and a number of other tensions that emerged across the data will be discussed in more detail in the meta-analysis.

In summary, there was a range of teaching practices arising from the understandings that the HPE teachers had expressed regarding curricula that were socially responsive and contextually relevant. These teaching practices included: authentic and embodied learning experiences which were located in the 'real world'; placing students on clinical platforms and immersing them in real communities; integration of medical and allied health disciplines through collaboration and multidisciplinary projects; modelling practices and values; using reflection to create students' awareness of contexts and health care systems; as well as getting students to think about how to act on their awareness.

\section{Meta-Analysis}

In answer to the research questions, the findings provided insights into how the participating HPE teachers understood the broad principles upon which their curriculum was built, as well as how their understandings translated into teaching practices. A further thematic meta-analysis conducted across all the transcripts revealed further insights and a number of cross-cutting tensions.

\section{Clinical competence vs critical consciousness}

Although the initial analysis indicated that the HPE teachers on the two programmes understood the need to develop students who were not only clinically competent but also critically conscious, there were differing views as to the relative importance of clinical competence and critical consciousness in the development of future healthcare professionals. Some respondents, 
particularly the clinicians, felt that more emphasis needed to be placed on the clinical competence, as illustrated in the quotations below:

I think from a clinician point of view, there is a worry ... there is a bit of concern with regards to time and content, and what are we letting go and squeezing more of that* [*referred to earlier in the transcript as 'acting as a change agent'] in here, how will it affect whether we will get everything ticked and done. (FG9)

... it's already such a big feat just to be a pure, if you take it purely as the doctor who heals, the clinician. Just the clinician part of a doctor is already overwhelming. I know that we must prepare the doctor for the other roles as well, but it should not impede or take away from the clinician. From the primary function. So, the social determinants of health, fixing those social determinants, is not the general practitioner's role. (FG7)

In contrast, other respondents saw the development of critical consciousness as vitally important, as illustrated below:

We should understand what are the needs of society, the health system, so then understand what does it need to do, to respond to the needs of society. The way that we train doctors should then be aligned with what is it that they need to do in that health system, in order to respond to the needs of society. That should then, in essence, inform our programmatic learning outcomes, the competencies that those doctors need to have in order to fulfil that role in the health system, and those programmatic learning outcomes would then inform what we actually do in the curriculum. (M26)

\section{Differing views of knowledge}

Another tension arising from the data related to differing views about knowledge. This was linked to the differing views about the relative importance of clinical competence and critical consciousness in the development of future healthcare professionals. Some respondents viewed the knowledge base informing clinical competence as the only knowledge base that mattered, as illustrated in the following exchange from one of the focus groups:

I think one of our biggest challenges is going to be, we need to address all of these things (referring to the broad principles underpinning the curriculum), there is no question about it, but I still think we should not do it at the expense of scholarship and knowledge, and that's going to be a huge challenge ... the increase in change and knowledge ... just in our basic sciences field, in physiology and what's going on on a molecular level, a cellular level, has been immense. So yes, so it's more of a rhetorical question I suppose, but how are we going to maintain and update the scholarship and knowledge, and improve on that? 
So, what's valued by their consultant is not context, community, being a change agent. It's about knowledge, and the fear of not having the knowledge, so rather than being, thinking and kind of questioning.

The feedback that we got back from the faculty was often things like this is a touchy-feely curriculum, and it's very $P C$.

And we need health experts.

And don't even have time for knowledge, we need more knowledge. (FG3)

This exchange illustrates the tension around what knowledge is valued but also around what is considered to be knowledge. It is clear that for these participants, biomedical knowledge is what matters and that the knowledge informing the being and becoming of a healthcare practitioner is considered 'touchy-feely'. It appears that awareness of 'context' and 'community', and being a 'change agent', is not considered knowledge at all. Throughout the data set this knowledge was referred to in various ways, as 'skills', 'attributes', 'attitudes', 'competencies', but never as knowledge.

\section{The role of change agent}

A third area of tension arising from the data related to how far HPE teachers needed to take the development of students' advocacy role and their agency to bring about change in the healthcare system, as illustrated in these views from one of the focus groups:

But my question is ... who must change the healthcare system ... should we, can we, in a way get our students to be active participants in it or what is needed to change. Because to change our healthcare system, the doctors that I think we produce deal with the issues on the ground fairly well, but that's not changing the system. You need the politicians and finance and engineers and other people to actually change the system ... if you as a doctor can get involved in that ... I mean, it's sending a hammer to tie a knot.

... there are so many boxes that one has to tick in preparing a healthcare professional ... but are we moving into the scope of other professionals? What is the social worker for? What is the Allied Health for? We should also then determine where our scope is ... the healthcare practitioner, the general practitioner should not assume that burden of having to fix a system. I don't think that's fair. (FG7)

This respondent was of the view that future healthcare practitioners could not be expected to 'fix' the healthcare system, because the healthcare system was caught up in so many other systems and roleplayers, all of which linked to the social determinants of health. He also felt that it was beyond the scope of an HPE teacher to develop in students an understanding of their possible roles within the complex relationship of sectors and other professionals. This links to the earlier discussion on interprofessional education. 
One respondent agreed with the view expressed above, that future healthcare practitioners should not be expected to become change agents in the healthcare system, however, he added that it was incumbent on the HPE teachers to create awareness of the social determinants of health, and to provide their students with the tools to bring about change if they chose to:

Not all doctors are there to become changers of the country. Some want to be plastic surgeons, that's it, doesn't have no interest in, and that's fair. You know, if you become a doctor, it doesn't mean that you are becoming a philanthropist, a person who wants to do fund raising and wants to uplift everybody ... I think that's an unfair expectation, to expect that every person who becomes a doctor would have to be that person. But every person who becomes a doctor, should be aware that there are social attributes, and if you are working in an environment, if it was your choice, or maybe sometimes not your choice, and you are placed in an environment where you are able, where it's expected of you to do it, we should have given them the tools to be able to do it. (M15)

A dilemma emerged, for some respondents, around whether it was ethical to go beyond sensitising students to a potential role that they could play as change agents:

You don't want to get students out there that live in La-La Land and think oh, we're going to change the world. I mean, that is also, you know, at the same time, our responsibility that we also make sure that they are aware of the realities. So on the one hand yes, you want to sensitise them, I think to me that's the most important, to these aspects. You know, the world has changed, we're in a different century now. It's not just the old style, diseasefocussed doctor that dishes out tablets. There is more to it now, and I think that's important... we just want to sensitise them to these other roles that they are playing in the community, or could play. (M6)

While this respondent was doubtful about whether future healthcare practitioners could bring about changes to the healthcare system, another respondent was more concerned about the potential dangers for students who might want to bring about change through whistleblowing:

But for me, that's an ethical dilemma, because / see these horrendous things happening to these cohorts of students. So they think through it to write the corrective action and they get a mark for it, but actually not correcting that behaviour that's going on. So it leaves me every year with this ethical dilemma of how far do we take this. And even though we cover, in the human rights things, things like whistle-blowing, it's a huge thing to expect a student, even a professional to be a whistle blower ... so that's an ethical thing for me. Do I teach them to be whistle blowers, when I actually know they are putting themselves at a disadvantage? I can't not teach them, so there is a huge amount of difficulty around it for 
me personally. But I take them to the point of identifying and saying what should be corrected. (P1)

This remained an unresolved tension in the data. While some respondents saw the need to only raise students' awareness of the realities of health inequity, others saw the need to prepare students to take on the role of change agent. While some respondents questioned whether it was the responsibility of a curriculum, or HPE teachers, to develop graduates who could take up the challenges of healthcare in South Africa, others saw this as integral to their teaching practice.

\section{Discussion}

The cross-cutting tensions discussed in the previous section raise questions about the relative importance of clinical competence and critical consciousness in the development of future healthcare professionals; what counts as knowledge; and about how far our responsibility extends in preparing students to take on the role of change agent. On the tension between the relative importance of clinical competence and critical consciousness, Kuper, et al. (2016) argue that knowledge beyond bioscience is needed in the training of physicians. We would argue that this is the case for all health professionals. Thomas, et al. (2020) propose that there should be a change in the content that is taught in HPE, with a shift in focus from biomedical knowledge towards knowledge from the 'social sciences'. Our contention is that both of these knowledge bases are equally important in the development of future healthcare professionals and that they need to be interwoven throughout HPE curricula.

On the related tension around what counts as knowledge, Kumagai and Lypson (2009) propose that critical consciousness, is a fundamentally different knowledge area to the kind of knowledge that is acquired in the biomedical sciences, and that it requires a change in the traditional relationship between HPE teachers and their students, as well as changes in how faculty development is undertaken and how programme goals are formulated. Thomas, et al. (2020) suggest that the legitimacy of various ways of knowing needs to be negotiated among stakeholders. We would argue that this tension is best managed through collaborative conversations (among curriculum designers, HPE teachers and educationalists) which make explicit what knowledge matters to whom, among all stakeholders. The purpose of such collaborative conversations would be reaching a shared understanding of the legitimacy of both knowledge bases (bioscience and social science) in developing clinical competence alongside critical consciousness in future healthcare professionals.

On the tension around how far HPE teachers should go in preparing students to take on the role of change agent, a recent study emanating from the South African context (ClitheroEridon, 2020: 1) found that while most of their respondents understood social accountability as 'requiring an action or set of actions', it was defined by some as simply 'the awareness one must have about the needs of their patients, community or society at large'. Their findings resonate with the findings from our study. We would argue that it is necessary for HPE teachers to go 
beyond simply creating awareness among their students of the realities of health inequity. They should also be preparing their students to take on the role of change agent by providing them with tools and strategies for taking up the challenges of unequal healthcare in South Africa. If we are to be guided by the literature, which calls for the foregrounding of ontological concerns in a higher education system which has been dominated by epistemological concerns, then we should heed the advice of Dall'Alba and Barnacle (2007: 683) when they suggest that

...for medical students, learning to know sicknesses and symptoms, in an embodied sense, would contribute to developing appropriate ways of acting towards patients, their friends and family, as well as relevant authorities and so on, in a manner that promotes improved health for patients. In other words, the focus of medical programmes would be developing appropriate ways of being medical practitioners, in contrast to simply acquiring and applying knowledge of relevance to medicine.

This advice would apply equally to HPE curricula from the Health Sciences. As suggested earlier in this paper, developing clinically competent but also critically conscious healthcare professionals in South Africa has implications for the role and identity of the HPE teachers who deliver such curricula. The role and identity of the HPE teacher is a crucial element in bridging the disconnect between the intentions of curriculum designers and the delivery of curricula. Bridging this disconnect requires engaging with issues of role and identity among curriculum designers, HPE teachers, and educationalists. This seldom forms part of the process of curriculum design and points to a re-envisioning of the role of HPE centres in the process of guiding responsive, socially just, curriculum renewal.

\section{Author Biographies}

Cecilia Jacobs is an Associate Professor in Higher Education Studies at the Centre for Health Professions Education at the University of Stellenbosch. Current research focuses on the question of knowledge and the importance of its centrality in debates on higher education teaching and learning.

Susan van Schalkwyk is Professor in Health Professions Education and Director of the Centre for Health Professions Education in the Faculty of Medicine and Health Sciences at Stellenbosch University. Research interests cover a range of topics related to learning and teaching, strengthening postgraduate supervision and academic writing.

Julia Blitz is a family physician by training, with a $\mathrm{PhD}$ in health professions education. She is currently the Vice-Dean: Learning and Teaching in the Faculty of Medicine and Health Sciences at Stellenbosch University. Her research interests are in faculty development, clinical training, selection, and curriculum renewal. 
Mariette Volschenk, M Phil., is a lecturer and PhD candidate at the Centre of Health Professions Education in the Faculty of Medicine and Health Sciences at Stellenbosch University. Her doctoral research focuses on the identity trajectories of health professionals involved in master's level health professions education studies.

\section{References}

Academy of Science of South Africa (ASSAf). 2018. Reconceptualising health professions education in South Africa. Pretoria: ASSAf. https://doi. org/10.17159/assaf.2018/0021

Barnett, R. 2005. Recapturing the universal in the university. Educational Philosophy and Theory, 37(6): 785-797.

Barnett, R. 2009. Knowing and becoming in the higher education curriculum. Studies in Higher Education, 34(4): 429-440.

Bawa, A. 2018. Universities need to 'rethink their purpose'. Speech at University of Pretoria annual Academic Achievers Awards. University of Pretoria News, 16 May 2018.

Bleakley, A., Brice, J. \& Bligh, J. 2008. Thinking the post-colonial in medical education. Medical Education, 42: 266-270.

Braun, V. \& Clarke, V. 2006. Using thematic analysis in psychology. Qualitative Research in Psychology, 3(2): 77-101.

Butler-Adam J. 2018. The Fourth Industrial Revolution and education. South African Journal of Science, 114(5/6).

Clithero-Eridon, A., Albright, D. \& Ross A. 2020. Conceptualising social accountability as an attribute of medical education. African Journal of Primary Health Care \& Family Medicine, 12(1), 2213. https:// doi.org/10.4102/phcfm. v12i1.2213

Dall'Alba, G. \& Barnacle, R. 2007. An ontological turn for higher education. Studies in Higher Education, 32(6): 679-691.

Frenk, J., Chen, L., Bhutta, Z.A., Cohen, J., Crisp, N., Evans, T. \& Zurayk, H. 2010. Health professionals for a new century: Transforming education to strengthen health systems in an interdependent world. The Lancet, 376(9756): 1923-1958.

Freire, P. 2000. Pedagogy of the Oppressed. 30th Anniversary Edition. New York, NY: Continuum.

Kumagai, A. \& Lypson, M. 2009. Beyond cultural competence: Critical consciousness, social justice, and multicultural education. Academic Medicine, 84(6): 782-787.

Kuper, A., Veinot, P., Leavitt, J., Levitt, S., Li, A., Goguen, J., Schreiber, M., Richardson, L. \& Whitehead, C. 2016. Epistemology, culture, justice and power: Non-bioscientific knowledge for medical training. Medical Education, 51(2): 158-173.

Lebel, J. \& McLean, R. 2018. A better measure of research from the global south. Nature, 23 (559): $23-26$.

Luckett, K. \& Shay, S. 2017. Reframing the curriculum: A transformative approach. Critical Studies in Education, DOI: 10.1080/17508487.2017.1356341

Marmot, M. 2005. Social determinants of health inequalities. Lancet, 365 (9464): 1099-1104. 
Mayosi, B. \& Benatar, S. 2014. Health and health care in South Africa - 20 years after Mandela. The New England Journal of Medicine, 371 (14): 1344-1353.

Mezirow J. 1990. Fostering Critical Reflection in Adulthood: A Guide to Transformative and Emancipatory Learning. San Francisco, CA: Jossey-Bass.

$\mathrm{Ng}, \mathrm{S}$., Kinsella, E., Friesen, F. \& Hodges, B. 2015. Reclaiming a theoretical orientation to reflection in medical education research: a critical narrative review. Medical Education, 49: 461-475.

Samuel, M., Dhunpath, R. \& Amin, N. (eds.). 2016. Disrupting Higher Education Curriculum: Undoing Cognitive Damage. Rotterdam: Sense Publishers.

Schön, D.A. 1983. The Reflective Practitioner: How Professionals Think in Action. New York, NY: Basic Books.

Scott, D. 2008. Critical Essays on Major Curriculum Theorists. London: Routledge.

Sherbino, J., Frank, J., Flynn, L. \& Snell, L. 2011. 'Intrinsic Roles' rather than 'armour': Renaming the 'non-medical expert roles' of the CanMEDS framework to match their intent. Advances in Health Sciences Education: Theory and Practice, 16: 695-697.

Thomas, A., Kuper, A., Chin-Yee, B. \& Park, M. 2020. What is "shared" in shared decision-making? Philosophical perspectives, epistemic justice, and implications for health professions education. Journal of Evaluation in Clinical Practice, 1-10. https://doi.org/10.1111/jep.13370

Van Schalkwyk, S., Herman, N. \& Muller, A. 2012. Graduate attributes for the public good: a case from a research-led university in South Africa. In Leibowitz, B. (ed.). Higher Education for the Public Good: Views from the South. Stoke on Trent: Trentham Books in association with SunMedia. 87-99.

Volmink, J. 2018. Reconceptualising health professions education in South Africa. South African Journal of Science, 114(7-8): 4-5.

Whitehead, C.R., Austin, Z. \& Hodges, B.D. 2011. Flower power: the armoured expert in the CanMEDS competency framework? Advances in Health Sciences Education: Theory and Practice, 16(5): 681-94. 